\title{
A benign teratoma of the ovary fistulating into the rectum
}

\author{
D Wickremasinghe ${ }^{1}$, D N Samarasekera ${ }^{1}$
}

\section{Introduction}

In Greek, teratoma means "monstrous tumour". Teratomas account for $10-20 \%$ of all ovarian neoplasms. More than $95 \%$ are benign (dermoid cysts) [1]. Less than $2 \%$ of cystic lesions contain malignant tissue, while more than $80 \%$ of solid teratomas are malignant [1].

\section{Case report}

A 39-year old mother of two children developed episodic left lower abdominal pain, alteration of bowel habit, haematochezia and occasional streaks of pus on stools of 6 months duration. She had regular 28 day menstrual cycles and had not used any contraceptives. There was no family history of ovarian, breast or colonic carcinoma. Clinical examination showed no abnormality in the abdomen. A sessile mass with a smooth surface was felt in the anterior rectal wall during digital rectal examination. Vaginal examination revealed a tender left adnexal mass. Flexible sigmoidoscopy showed a friable sessile lesion (about $2 \mathrm{~cm}$ in size) with a cluster of hair protruding through it. The biopsy showed inflammatory changes only.

A contrast enhanced CT of the abdomen showed a heterogeneous mass in the left pelvis, behind the bladder. It contained fat, bone and soft tissue densities. The wall was thick and irregular, and merged with the serosal surface of the rectum. The patient underwent resection of the left ovary, the 'tumour' and the involved section of the rectum ("anterior resection") followed by a stapled rectal anastomosis. She had an uneventful recovery. Macroscopically the mass contained a cystic and solid tumour with a tuft of hair and two teeth (Figure 1). The histology of the resected specimen was consistent with a mature cystic teratoma containing stratified squamous epithelium, respiratory epithelium, pilosebaceous units, adipose tissue, cartilage and lymphoid tissue. There was no evidence of malignancy.

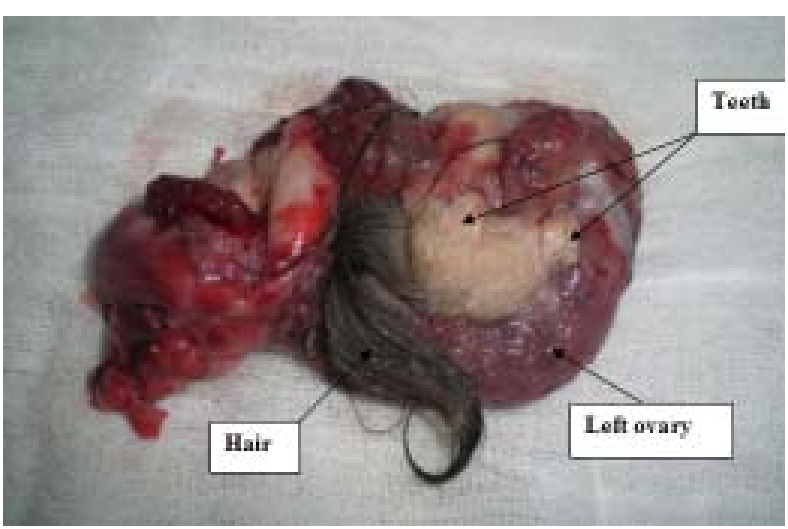

Figure 1. Excised teratoma, showing hair and teeth.

\section{Discussion}

Despite the high incidence of ovarian teratomas and the anatomical proximity to the rectum, there have been only a handful of documented cases of ovarian teratomas with rectal involvement, the first being reported in 1953 $[1,2]$. CT is the best imaging modality for the diagnosis of ovarian teratomas [4]. In our patient, according to the CT, the 'tumour' appeared to merge with the rectum. Since malignancy could not be excluded preoperatively, we carried out an en-bloc resection of the upper rectum.

\section{References}

1. Landmann DD, Lewis RW. Benign cystic ovarian teratoma with colorectal involvement. Report of a case and review of the literature. Diseases of Colon and Rectum 1988; 31: 80813.

2. Chehab F, Khaiz D, Lakhloufi A, et al. Ovarian teratoma prolapsed into the rectum. Annales de Chirurgie 1998; 52:101.

3. Russo M. Ovarian dermoid cysts breaking the wall of the rectosigmoid. Archivio Italiano Dianatomia Eistologia Patologica 1953; 26: 264-73.

4. Buy JN, Ghossain MA, Moss AA, et al. Cystic teratoma of the ovary: CT detection. Radiology 1989; 171: 697-701.

\footnotetext{
${ }^{1}$ Department of Surgery, Faculty of Medicine, University of Colombo, Sri Lanka.

Correspondence: DNS, e-mail <samarasekera58@yahoo.co.uk>. Received 23 March and accepted 7 August 2010. Competing interests: none declared.
} 